\author{
영상처리기법을 이용한 스톨 사육 모돈의 인공수정적기 예측 \\ 장치 개발 \\ 김동주* . 연성찬** . 장홍희*** \\ 합천사료*, 경상대학교 수의학과**, 경상대학교 축산학전공 · 농업생명과학연구원***
}

\title{
Development of a Device for Estimating the Optimal Artificial Insemination Time of Individually Stalled Sows Using Image Processing
}

\author{
D. J. Kim*, S. C. Yeon** and H. H. Chang*** \\ Hapcheon Feed Co., Hapcheon 678-813, Republic of Korea*, \\ Department of Veterinary Medicine, College of Veterinary Medicine, Gyeongsang National University, \\ Jinju 660-701, Republic of Korea**, \\ Department of Animal Science and Technology • Institute of Agriculture and Life Sciences, Gyeongsang \\ National University, Jinju 660-701, Republic of Korea***
}

\begin{abstract}
The goal of this study was to develop an optimal artificial insemination time estimator (OAITE) for individually stalled sows using image processing and to evaluate the performance of the OAITE through field test. The OAITE consisted of a computer, a multiplexer, three CCD cameras and three LED lamps (950nm wavelength). The computer program used for the OAITE to quantify the lying and non-lying (sitting and standing) rates of sows in stalls was written in LabWindows/CVI. For the purpose of establishing references that would help estimate the optimal artificial insemination(AI) time for sows, the lying rate of the 50 Berkshire $\times$ Hampshire crossbred sows (parity: 2 to 7) was observed and recorded. The observation was made from the second day after the sows were moved into the stalls when they were artificially inseminated. The results of above process, which compared the lying rates of the day of estrus and the other days, showed that there were no significant differences at the following time bands: 00, 08, 09,16 , and $17(\mathrm{p}>0.1)$. Thus, only the time bands other than these time bands were used to establish the references for determining the onset of the estrus. Based on the lying rates observed and the references established by the procedures above, the study assigned " 0 " to the lying rate of the non-estrus time band, " 0.5 " to the lying rate between the non-estrus and estrus time bands and " 1 " to the lying rate of the estrus time band. The authors of the study assumed that if the OAITE produced " 0.5 " or above more than 4 times in a row and if the results included " 1 " at least once, the estrus would have started. In addition, it was assumed that the optimal AI time for sows was between the 26th hour and the 34th hour after the beginning of estrus. The results of sows' AI of the OAITE group $(n=40$ sows; $A I=1$ time $)$ showed that the pregnancy rate was $92.5 \%$, which was the same rate as the control group $(n=40$ sows; $A I=2$ times), and that the litter size did not differ between the control and the OAITE group. These data suggest that the OAITE might be effective and economic to estimate the optimal AI time of individually stalled sows. (Key words : Sow, Estrus, Artificial insemination, Estimation, Image processing)
\end{abstract}

Corresponding author : H. H. Chang, Department of Animal Science and Technology • Institute of Agriculture and Life Sciences, Gyeongsang National University, Jinju 660-701, Republic of Korea. Tel : +82-55-7515510, E-mail: hhchang@gnu.ac.kr 


\section{I. 서 론}

돼지를 포함한 대부분의 동물은 일정한 발정 주기를 가지고 일정한 시기에 배란을 하는 자 연배란동물이지만, 토끼, 고양이, 밍크 등의 암 놈은 교미자극에 의해 배란이 일어나는 유기배 란동물이다. 또한 1년에 한 번만 발정하는 단 발정동물과 1 년에 수차례 발정하는 다발정동물 이 있다. 이 중에서 모돈은 1년에 수차례 발정 하는 다발정 동물로서 발정기에 들면 비발정기 와는 다른 행동을 나타낸다 (Diehl 등, 2001).

양돈가의 수익을 최대화하기 위해서는 비생 산일수를 최소로 줄여야 한다. 모돈의 비생산 일수를 줄일 수 있는 한 가지 방법은 성공적으 로 교배를 시키는 것이다. 이처럼 성공적으로 교배를 시키기 위해서는 수정적기를 정확히 예 측해야 한다. 만약 수정적기를 정확히 판단하 지 못하여 수태가 되지 않으면, 비생산일수가 늘어나 손실을 입게 된다. 따라서 수정적기를 정확히 판단하는 것은 모돈의 성공적인 인공수 정에 있어서 중요한 요소이다. 수정적기는 배 란이 일어나기 전 10 시간에서 12 시간 사이이 며, 발정이 시작되는 시점을 기준으로 하였을 때 경산돈의 경우 26 시간에서 34 시간 사이이고 미경산돈의 경우는 18 시간에서 26 시간 사이이 다 (Evans 등, 2001). 현재 하루에 두 번 모돈의 발정을 확인하는 것이 일반화되어 있으며, 이 때 웅돈을 접촉시키거나 육안관찰을 통하여 발 정 유무를 판단한다. 이러한 방법에는 숙련된 기술과 풍부한 경험이 요구될 뿐만 아니라 총 소요노동력의 $30 \%$ 정도가 요구된다(Perez 등, 1986). 하루에 두 번밖에 발정을 감지하지 않기 때문에 발정이 언제 시작되었는지를 정확히 알 수 없으며, 또한 발정의 대부분이 새벽에 시작 되므로 수정적기를 정확히 판단하기란 매우 어 렵다. 만약 발정을 감지했더라도 적기에 인공 수정을 하지 못한다면, 수태율이 낮아지므로 경제적 손실이 초래된다. 현재 이러한 문제점 때문에 2회에서 3 회에 걸쳐 인공수정을 하고 있으나 이에 따른 소요비용과 소요노동력 등
은 양돈가의 부담을 가중시키는 요인이 되고 있다.

돼지는 발정기가 되면 비발정기에 나타내지 않던 외음부의 냄새를 맡는 행동, 귀를 세우는 행동 및 승가허용 행동 등을 나타낸다 (Diehl 등, 2001). 또한 돼지는 비발정기에 비하여 발 정기에 더 많은 활동량을 나타낸다 (Altman,

1941; Erez and Hartsock, 1990). Freson 등(1998) 은 스톨에서 개별적으로 사육되고 있는 모돈의 활동량을 적외선센서를 이용하여 측정함으로써 발정을 $86 \%$ 까지 감지하였다고 보고하였다. 그 러나 이 연구는 단지 모돈의 발정을 감지하였 을 뿐 번식관리에 있어서 가장 중요한 수정적 기의 판단 기준을 제시하지 못하였다.

따라서, 본 연구는 스톨에서 사육되는 모돈 의 활동량을 측정함으로써 발정시작시각을 감 지하고 이를 기준으로 인공수정적기를 예측할 수 있는 인공수정적기 예측 장치를 개발한 후 이의 성능을 농장실증실험을 통하여 시험하고 자 수행되었다.

\section{ㅁ. 재료 및 방법}

\section{1. 공시동물 및 실험시기}

2 7산차인 버크셔 × 햄프셔 교잡종(F1) 모돈 총 130 두가 공시되었다. 이 중에서 발정시작시 각 감지 기준 및 인공수정적기 예측 기준을 설 정하는데 50두가 이용되었으며, 나머지 80 두(대 조구: 40 두, 실험장치구: 40 두)는 개발된 인공수 정적기 예측 장치의 성능을 평가하는데 이용되 었다. 공시동물은 이유 직후 스톨에 입식시켜 발정을 감지하고 인공수정을 실시한 다음 다른 스톨로 이동시켜 임신말기까지 사육하는 방식 으로 관리되었다. 사료는 하루에 두 차례에 걸 쳐 08 시경과 16 시경에 약 $1.5 \mathrm{~kg}$ 씩 급여하였으 며, 물은 니플을 이용하여 공급하였다.

모돈은 더위 스트레스를 받지 않는 겨울, 봄 및 가을에 비하여 더위 스트레스를 받는 여름 에 낮에는 덜 활동하고 밤에는 많이 활동을 하 
게 된다. 따라서 모돈의 활동량을 측정하여 발 정시작시각을 감지하고 인공수정적기를 정확히 예측하기 위해서는 크게 여름과 여름을 제외한 나머지 계절 (봄, 가을, 겨울)로 나누어 기준을 설정해야 할 것으로 판단된다. 본 연구는 여름 을 제외한 나머지 계절 동안에만 수행되었다.

\section{2. 돈사시설}

실험에 이용된 돈사는 모돈 250두 정도를 수 용할 수 있는 7 열의 스톨 $(2.30 \mathrm{~m} \times 0.65 \mathrm{~m})$ 이 돈사 길이 방향으로 나열되어 있는 무창돈사이었으 며, 바닥은 콘크리트바닥이었다. 돈사 내부의 환경은 팬과 자동제어기에 의하여 자동으로 조 절되었다. 06시부터 백열등을 이용하여 인공적 으로 조명을 실시하다가 해가 뜬 후에는 백열 등을 소등하고 창문을 통하여 들어오는 자연광 을 이용하여 빛을 제공하였다. 그리고 이처럼 자연광을 이용하여 빛을 계속 제공하다가 해가 지기 직전부터 21시까지는 백열등을 이용하여 다시 인공적으로 조명하였다.

\section{3. 발정시작시각 감지 기준 설정방법}

모돈 50 두의 행동을 입식 직후부터 인공수정 때까지 CCD 카메라 (SBC-340, Korea), 멀티플렉 서 (SDM-080, Korea), Time lapse VCR (SRV-30, Korea), 비가시영역(파장:950nm)의 다이오드 (AUK SI5312-H, Korea)로 구성된 LED램프를 이용하여 녹화한 후 Taylor 등 (1988)과 Worobec 등 (1999)이 사용한 행동별 관찰기준에 따라 누 워 있는 행동 (lying), 앉아 있는 행동(sitting), 그 리고 서있는 행동 (standing)으로 구분하여 1 분 간격으로 관찰하였다.

발정시작시각 감지 기준을 설정하기 위해서 는 명확히 구분된 비발정기 행동 데이터와 발 정기 행동 데이터가 필요하다. 이유 직후의 모 돈은 입식한 날에 새로운 환경에 대하여 탐색 행동을 나타낸다 (Taylor and Friend, 1988). 그러
므로 입식한 날의 행동 데이터가 비발정기의 행동 데이터에 포함되지만 발정시작시각 감지 기준을 설정하기 위한 비발정기 행동 기준 데 이터로 이용돼서는 안 된다. 또한 비발정기에 서 발정기로 넘어가는 과도기의 데이터가 이용 될 경우 발정시작시각을 판단하는데 혼란을 초 래할 수 있기 때문에 과도기의 데이터도 발정 시작시각 감지 기준을 설정하기 위한 비발정기 행동 기준 데이터로 이용돼서는 안 된다.

발정 감지는 스톨에 입식한 다음 날부터 최 초 발정이 감지될 때까지 하루에 두 번 07시경 과 18 시경에 관행의 방법에 따라 실시하였다. 즉, 모돈이 웅돈 앞에서 관리자가 모돈의 등에 올라탔을 때 (back pressure test) 승가허용자세를 취함과 동시에 외음부에서 점액이 관찰되고 외 음부가 부풀어 있을 때 발정으로 간주하였다. 발정시작시각은 승가허용자세가 처음 관찰된 시간을 기준으로 5시간을 뺀 시간으로 하였으 며 (Nissen 등, 1997), 이 발정시작시각부터 24시 간 후까지의 데이터가 경산돈의 발정이 32시간 부터 96시간까지 지속되는 점 (Weitze 등, 1994) 을 고려해 볼 때 발정기 행동 기준 데이터로 이용되는 것이 타당할 것으로 판단된다.

누워 있는 행동 비율은 시간대별로 다르게 나타나기 때문에 발정시작시각을 정확히 감지 하기 위해서는 시간대별로 비발정기 데이터와 발정기 데이터를 비교할 필요가 있다. 그리고 누워 있는 행동 비율에 있어서 어떤 시간대에 서는 비발정기와 발정기 사이에 통계적 유의차 가 없을 수 있고 이러한 데이터가 발정시작시 각을 감지하는 기준을 설정하는데 이용될 경우 발정시작시각을 감지하는데 혼동이 초래될 수 있다.

따라서 발정시작시각 감지 기준을 설정하는 데 발정 2 일전과 발정 당일의 데이터만을 이용 하였으며, 시간대별로 비발정기와 발정기 사이 에 통계적 유의차를 확인한 후 유의차가 없는 데이터는 발정시작시각 감지 기준을 설정하기 위한 데이터에서 배제하기 위하여 발정 2일전 
과 발정당일 사이의 누워있는 행동 시간 비율 에 대하여 시간대별로 sign-test를 실시하였다 (SPSS, version 9.0).

발정시작시각 감지 기준을 설정하기 위하여 육안으로 관찰한 모돈 50 두에 대한 발정 2일전 과 발정 당일의 시간대별 누워 있는 행동 비율 을 구한 후 이에 대한 $95 \%$ 신뢰구간의 하한값 과 상한값을 구하였다. 그리고 시간대별 비발 정구간은 비발정기 누워 있는 행동 비율의 95\% 신뢰구간 하한값부터 $100 \%$ 이하의 구간으 로 정의하였으며, 시간대별 발정구간은 $0 \%$ 부터 발정기 누워 있는 행동 비율의 $95 \%$ 신뢰구간 상한값 미만의 구간으로 정의하였다. 특정시간 대의 누워 있는 행동 비율이 비발정구간에 위 치할 경우에는 0 , 또는 비발정구간과 발정구간 사이에 위치할 경우에는 0.5 , 또는 발정구간에 위치할 경우에는 1 로 결정하였다. 이러한 값 $(0$, $0.5,1)$ 의 연속성을 확인하였을 때 0.5 이상의 값이 4번 연속하여 나타나고 이중에 1 이 한 번 이상 포함되어 있으면 발정으로 간주하고 이들 시간 중에서 처음 시간을 발정시작시각으로 판 단하였다. 그러나 0.5 이상의 값이 4 번 연속하 여 나타났으나 이 중에 1 이 한 번도 포함되지 않을 경우 비발정으로 판단하였다.

\section{4. 인공수정적기 예측 기준 설정방법}

모돈의 인공수정적기는 배란이 언제 일어나 는가에 따라 결정된다. Weitze 등(1994)에 의하 면, 경산돈의 평균 발정지속시간은 64시간이고, 배란은 발정지속시간을 4 등분하였을 때 평균적 으로 4 분의 3 에 해당되는 시간에 일어난다 (Soede 등, 1995; Weitze 등, 1994). Soede 등 (1996)은 배란 전 0 24시간에 수정을 해야 한 다고 보고하였고, Evans 등(2001)은 발정시작 후 26 34시간이 수정적기라고 보고하였다. 이 상의 결과들을 종합적으로 고려하여 발정시작 시각 후 26시간부터 34시간 사이를 수정적기로 판단하였다.

\section{5. 실험장치의 구성}

(1) 하드웨어

스톨 내에서 사육되는 모돈은 발정기가 되면 앉아 있는 행동과 서 있는 행동의 증가를 나타 내는 반면 누워 있는 행동의 감소를 나타내는 특징을 가지고 있다(Erez and Hartsock, 1990; Freson 등, 1998). 본 연구에서는 이러한 모돈의 행동특성을 이용하여 모돈이 서 있거나 앉아 있는 행동의 비율을 시간대별로 1 분 간격으로 측정함으로써 발정시작시각을 감지한 후 이를 기준으로 인공수정적기를 예측할 수 있도록 Fig. 1 과 같이 인공수정적기 예측 장치를 구성 하였다. 인공수정적기 예측 장치의 작동원리는 다음과 같다. Fig. 1의 (3) CCD camera가 스톨 의 후면부에 고정되어 있는 Fig. 1 의 (4) LED lamp의 빛(비가시영역의 파장 : 950nm)에 대한 영상을 획득한다. 만약 모돈이 누워 있으면 LED lamp의 빛이 그대로 획득이 되고, 만약 모돈이 앉아 있거나 서 있으면 LED lamp의 빛 이 모돈에 의해 가려져서 획득이 되지 않는다. 이와 같이 Fig. 1의 (3) CCD camera에 의해 획 득된 영상은 Fig. 1의 (2) multiplexer를 통하여 Fig. 1의 (1) PC로 전달된다. 채널별로 $\mathrm{PC}$ 로 전

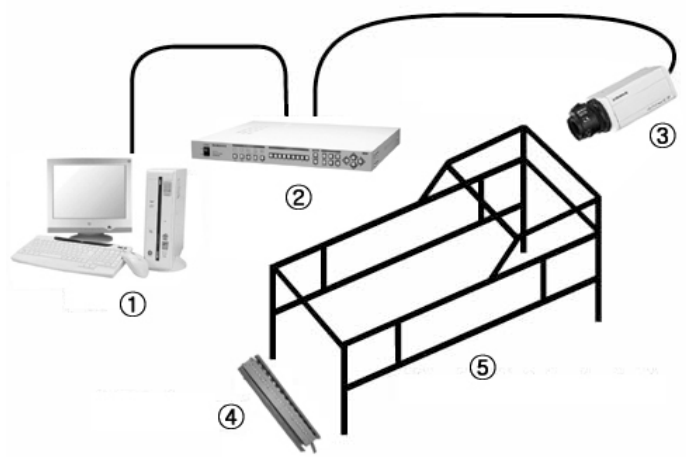

(1) PC (2) Multiplexer (3) CCD camera

(4) LED lamp (5) Stall

Fig. 1. The schematic diagram of the device for estimating the optimal artificial insemination time of individually stalled sows using image processing. 
달된 영상을 프로그램으로 처리하여 모돈의 행동을 누워 있는 행동과 앉아 있거나 서 있 는 행동으로 구분하여 이들 행동의 비율을 측 정한다.

실제 돈사에서 인공수정적기 예측 장치의 성 능을 평가하기 위하여 Fig. 2와 같이 실험장치 를 종부사에 설치한 후 모돈 40두를 대상으로 발정시작시각 감지 여부 및 정확도, 인공수정 적기 예측 시간의 정확도, 수태 여부, 그리고 산자수 등을 평가하였다. Fig. 2에 있는 스톨의 크기는 $640 \mathrm{~mm}(\mathrm{~W}) \times 2,000 \mathrm{~mm}(\mathrm{~L}) \times 1,000 \mathrm{~mm}(\mathrm{H})$ 이었다. CCD camera는 Fig. 2의 (1)과 같이 스 톨 전면부로부터 $90 \mathrm{~cm}$ 앞쪽 그리고 바닥으로 부터 $120 \mathrm{~cm}$ 높이에 설치되었으며, LED lamp는 Fig. 2의 (2)와 같이 스톨 후면부에 바닥으로부 터 $30 \mathrm{~cm}$ 높이에 설치되었다. LED lamp의 길이 는 $45 \mathrm{~cm}$ 이었다.

\section{(2) 소프트웨어}

인공수정적기 예측 장치의 프로그램은 LabWindows/CVI(Version 6.0.1)로 작성되었으며, 프로그램의 주 화면은 Fig. 3과 같다. 주 화면 의 캔버스에는 8채널까지 영상을 획득하여 나 타낼 수 있도록 프로그램이 작성되었으나 실제

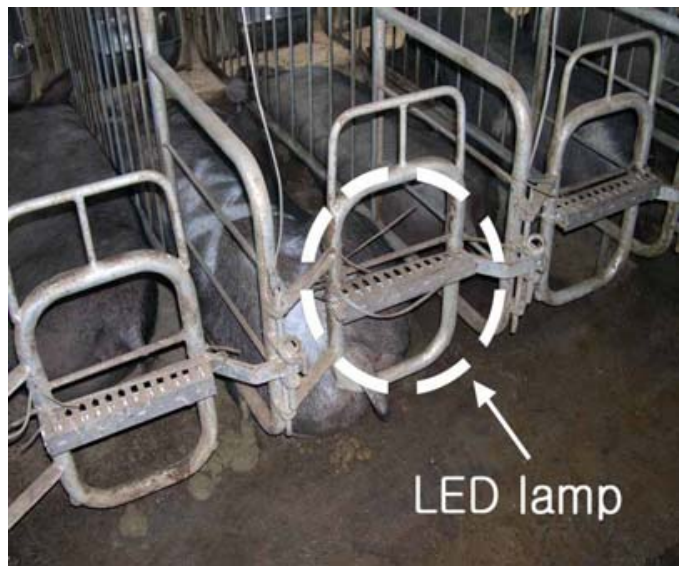

(1) CCD camera
로 3채널만 이용하여 실험하였기 때문에 Fig. 3 의 캔버스에는 3 채널 영상만이 획득되어 나타 내어졌다. Fig. 3의 캔버스에 나타낸 영상은 실 제로 흑백 CCD camera에 의해 획득된 영상이 며, 1 번 채널, 2 번 채널, 그리고 3 번 채널의 경 우 모돈이 모두 누워 있어 화면중간부분의 $\mathrm{LED}$ lamp의 빛이 전혀 가려짐 없이 획득된 것 을 볼 수 있다.

Fig. 4는 획득된 영상을 이진화한 것을 예로 나타낸 것이다. 각 채널별로 중간부분에 적색 의 사각형이 있는데, 이 부분에 LED lamp의 빛이 들어오도록 하였다. 주변의 환경변화에 관계없이 모돈의 행동을 정확하게 판단하기 위 하여 이 적색 사각형 내의 영상만을 가지고 모 돈의 행동을 판단하였다. 적색 사각형 내의 총 픽셀 수는 60 이었다. 이 중에서 30 픽셀 이상 이 LED lamp의 빛으로 판단되면 1 로 결정하였 으며, 30 픽셀 미만이 LED lamp의 빛으로 판 단되면 0 으로 결정하였다. 이때 $\mathrm{R}, \mathrm{G}$, 그리고 $\mathrm{B}$ 의 경계값을 모두 240으로 하여, 각 값이 240 이상일 때만이 흰색으로 획득되고 나머지는 흑 색으로 획득되었다. Fig. 4의 캔버스에서 1번 채널과 2 번 채널의 경우는 모돈이 누워 있어 적색 사각형 내에 각각 56 픽셀의 $\mathrm{LED}$ lamp

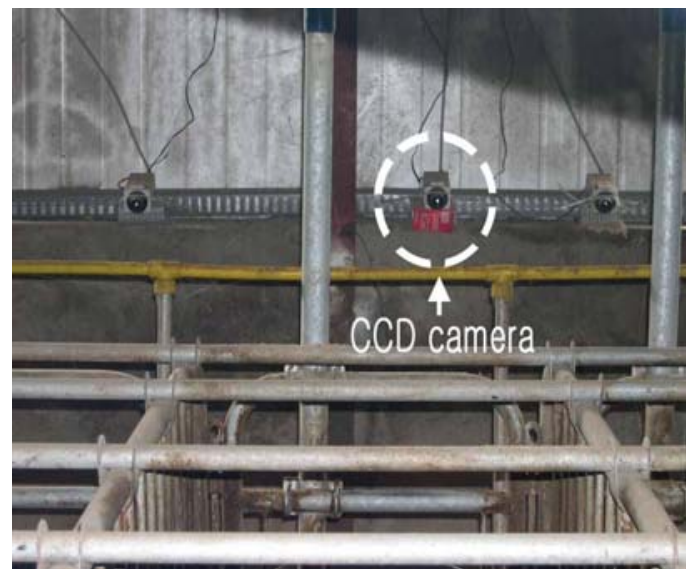

(2) LED lamp

Fig. 2. Photograph of the device for estimating the optimal artificial insemination time. 


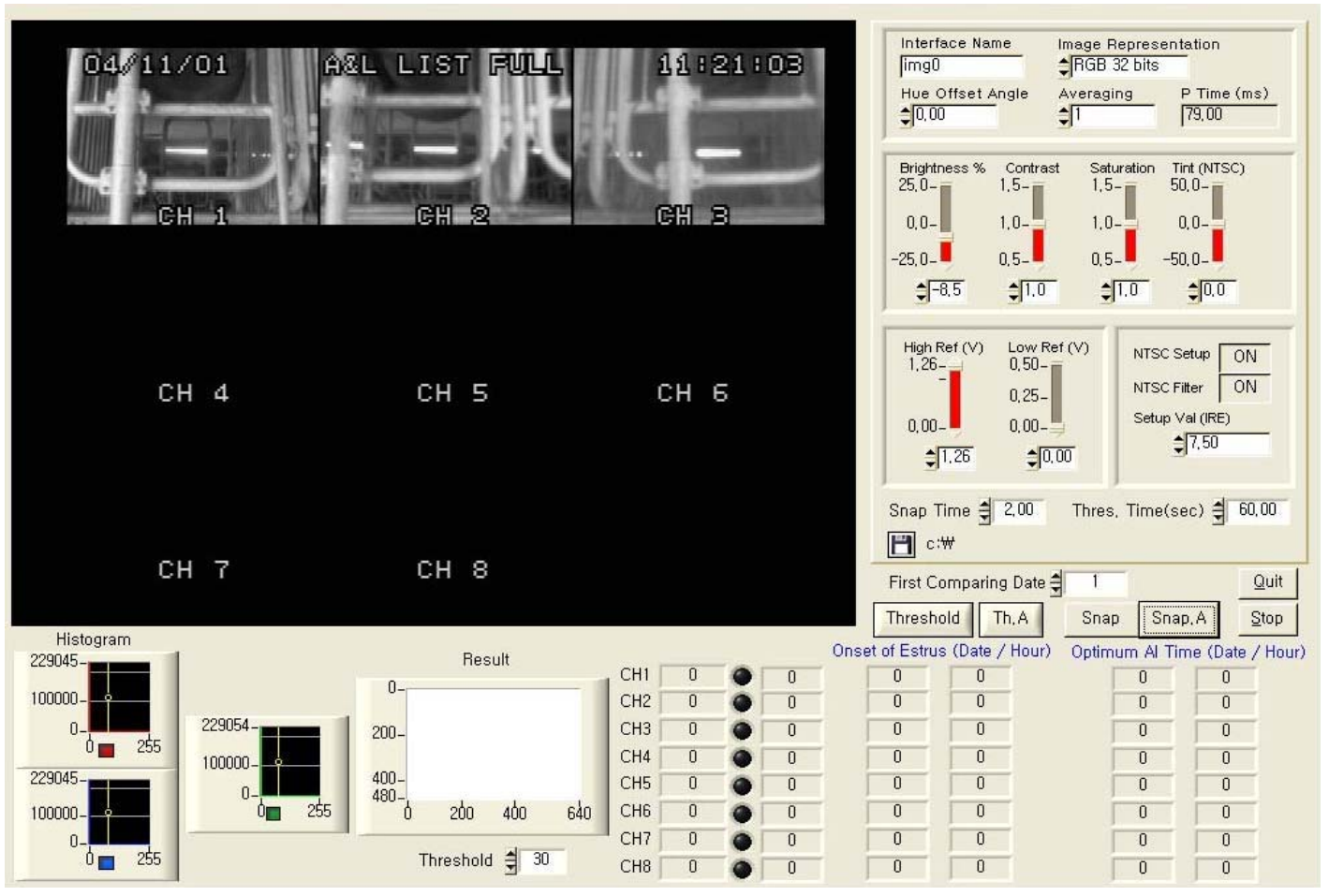

Fig. 3. Main menu of the program for estimating the optimal insemination time.

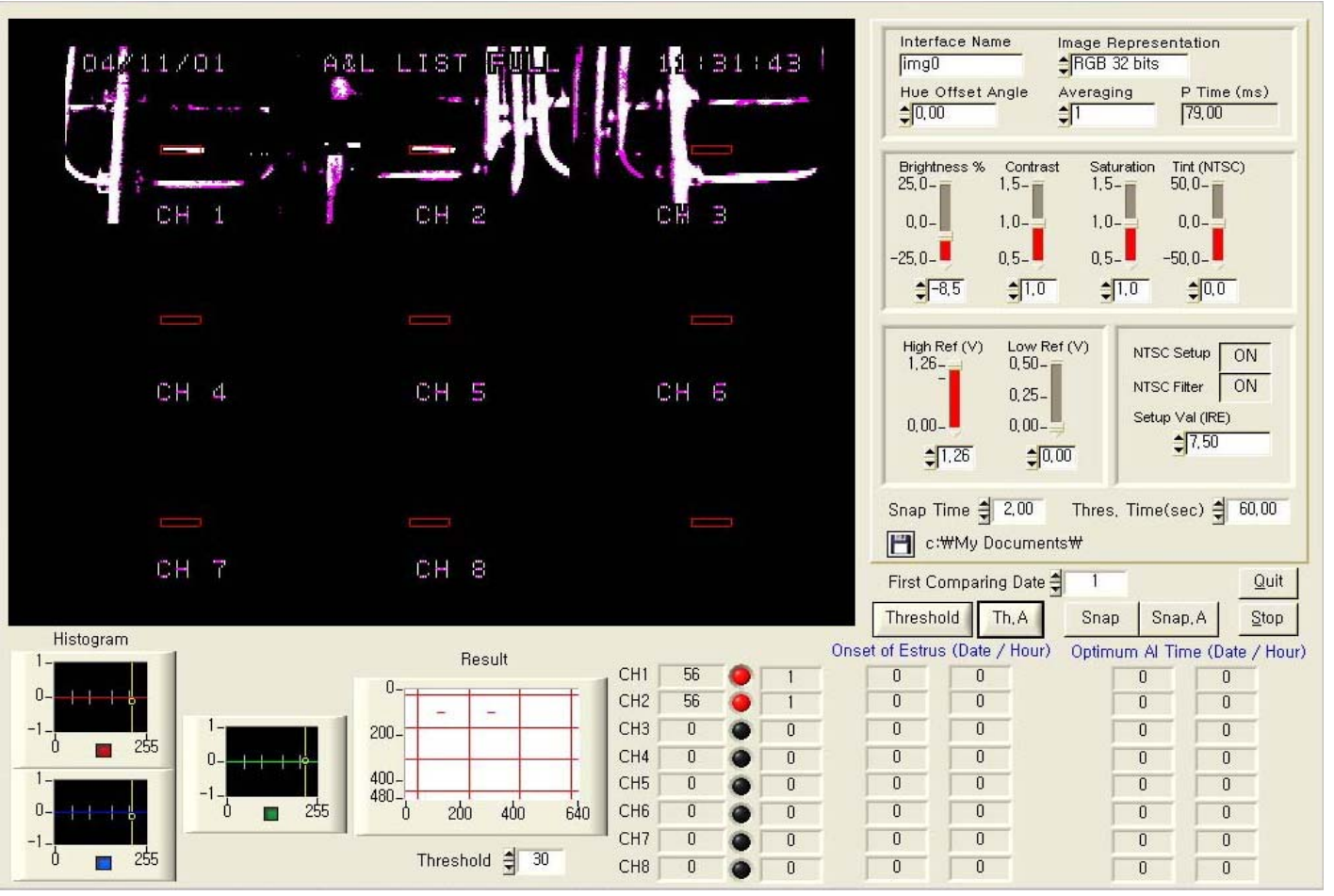

Fig. 4. Binary images processed by the program. 
빛이 획득된 것을 알 수 있는 반면에, 3번 채 널의 경우는 모돈이 앉아 있거나 서 있어 적 색 사각형 내에 LED lamp 빛이 전혀 획득되지 않은 것을 알 수 있다. 모돈의 행동 측정 결 과, 발정시작시각, 그리고 인공수정적기 등은 Fig. 4와 같이 화면 오른쪽 하단에 표시되도록 하였다.

\section{6. 실험장치의 성능 평가}

실제 돈사에서 대조구 40 두와 실험장치구 40 두를 대상으로 발정감지율, 수태율, 분만율, 평 균 복당 산자수, 평균 복당 사산수 및 평균 복 당 미이라수에 대한 실험장치의 성능을 평가하 였다. 평균 복당 산자수와 평균 복당 사산수에 대한 대조구와 실험장치구 사이의 통계적 유의 차 검정은 SAS(SAS Institute, 1998)의 GLM을 이용하여 실시하였다.
III. 결과 및 고찰

\section{1. 모돈의 비발정기와 발정기 행동특성}

Fig. 5는 모돈 50 두에 대한 비발정기와 발정 기의 24시간 시간대별 누워 있는 행동 비율의 평균값과 $95 \%$ 신뢰구간의 하한값 및 상한값을 나타낸 것이다.

보통 군으로 사육되는 모돈의 경우 발정기에 도달하면 수퇘지를 찾는 행동을 많이 나타내 고, 특유한 소리를 내며, 주위를 돌아다니게 된 다. 그러나 스톨에서 개별적으로 사육되는 모 돈의 경우에는 움직임의 제한 때문에 비발정기 에 비하여 더 많이 서 있거나 앉아 있게 된다 (Morrison 등, 1986). 본 실험에 이용된 모돈들 도 Fig. 5와 같이 동일한 결과를 나타내었다. 또한 Ingram 등(1980)과 Bressers 등(1991)이 보 고한 바와 같이 모돈은 밤보다 낮에 많이 서

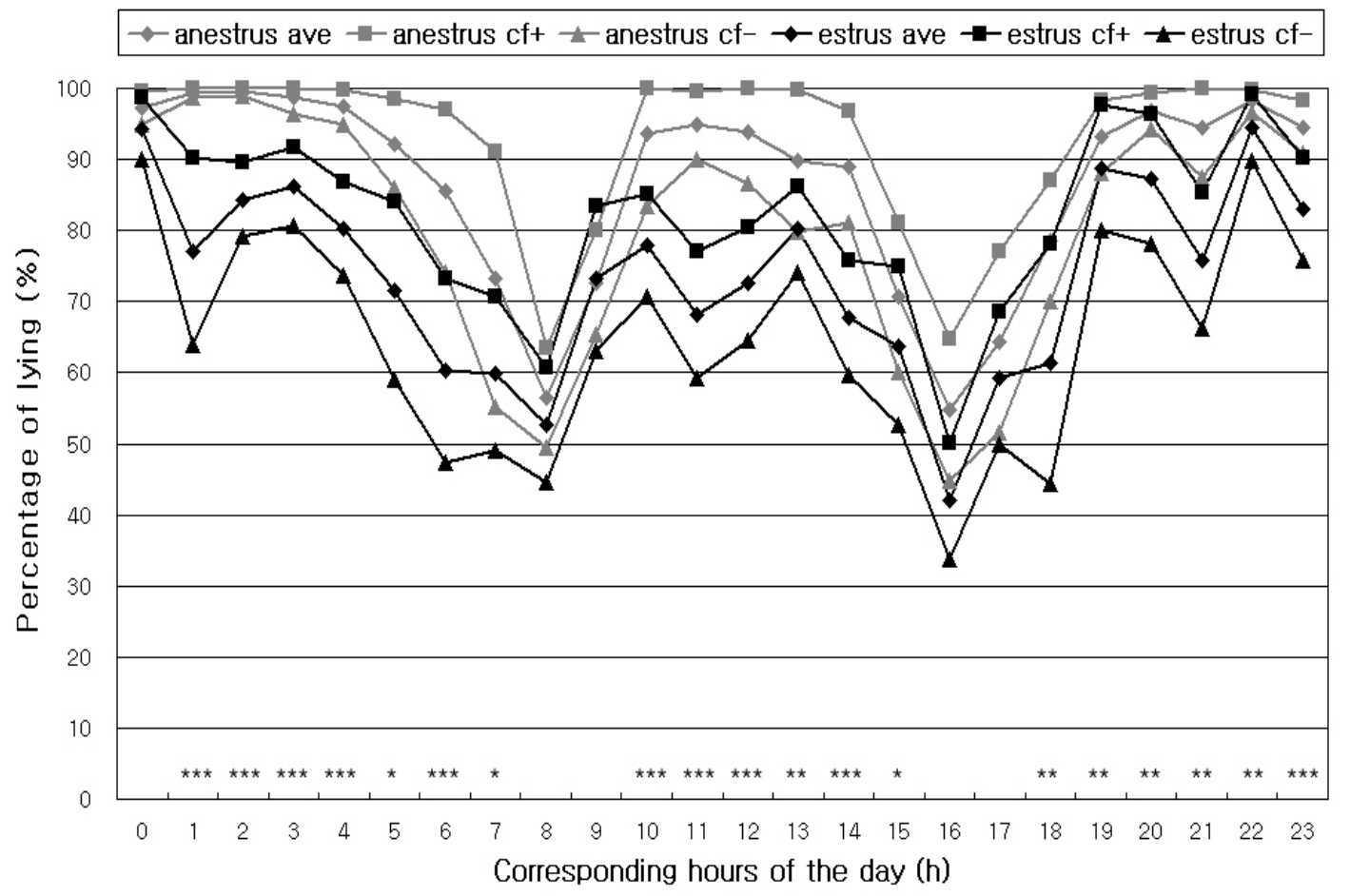

Fig. 5. Means and 95\% confidence levels of lying rates in sows.

$\left(^{*}: \mathrm{p}<0.1,{ }^{* *}: \mathrm{p}<0.05, * * *: 0.01\right)$ 
있거나 앉아 있는 경향을 나타내었다.

모돈들은 Fig. 5와 같이 08시경과 16시경에 사료가 공급되는 것을 미리 알고 07 시대와 15 시대부터 서서 사료를 요구하는 행동을 나타내 기 시작하였고(Houpt, 1991; Mistlberger 등, 1990), 실제로 사료가 공급된 08 시경과 16 시경에는 서 서 사료를 섭취하였다. 이러한 이유 때문에 07 시대, 08시대, 15시대, 그리고 16시대의 누워 있는 행동 비율이 낮게 나타났다. 또한 조명이 켜지고 꺼지는 시간대인 06시대 및 21시대 그 리고 작업자가 작업을 주로 하는 09시대 및 17 시대에도 마찬가지로 누워 있는 행동 비율이 낮게 나타났다. 이러한 시간대의 누워 있는 행 동 비율이 발정시작시각 감지 기준을 설정하는 데 이용된다면 발정시작시각의 감지율이 낮아 질 수 있기 때문에, 시간대별로 비발정기와 발 정기 사이의 유의차를 검정하여 유의차가 나타 나지 않는 시간대를 찾아낸 후 이들 시간대의
데이터를 발정시작시각 감지 기준을 설정하기 위한 데이터에서 제외하여야 한다. 따라서 발 정 2일전 24시간 데이터와 발정 당일 24시간 데이터를 가지고 시간대별로 비발정기와 발정 기사이의 유의차를 검정하였는데, Fig. 5와 같 이 00시대, 08시대, 09시대, 16시대, 그리고 17 시대에는 유의차가 나타나지 않았으나 $(\mathrm{p}>0.1)$ 다른 시간대에는 유의차가 나타났다. 이처럼 08시대, 09시대, 16시대 및 17시대에 유의차가 나타나지 않은 이유는 사료섭취와 작업자의 작 업에 의하여 많이 서 있거나 앉아 있었기 때문 이었다. 그러나 00 시대에 유의차가 나타나지 않은 이유는 알 수 없었다. 따라서 발정 2일 전의 24시간 데이터와 발정 당일 24시간 데이 터 중에서 유의차가 나타나지 않은 00 시대, 08 시대, 09시대, 16시대, 그리고 17시대의 데이터 를 제외한 나머지 시간대의 데이터만을 발정시 작시각 감지 기준을 설정하는데 최종적으로 이

Table 1. The non-continuity of more than 0.5 during anestrus

\begin{tabular}{l|l|l|l|l|l|l|l|l|l|l|l|l|l|l|l|l|l|l|l}
\hline Sow Hour & 01 & 02 & 03 & 04 & 05 & 06 & 07 & 10 & 11 & 12 & 13 & 14 & 15 & 18 & 19 & 20 & 21 & 22 & 23 \\
\hline \hline bh 278 & 1 & 0 & 0 & 0 & 0 & 0 & 0.5 & 0.5 & 0 & 0 & 0 & 0 & 1 & 0 & 0.5 & 1 & 0 & 0 & 1 \\
\hline bh 425 & 0.5 & 0 & 0 & 0 & 0 & 0 & 0 & 0.5 & 0.5 & 0.5 & 0 & 0 & 0 & 0 & 1 & 0 & 0.5 & 0.5 & 0 \\
\hline bh 427 & 1 & 0 & 0 & 0 & 0 & 1 & 1 & 0 & 1 & 0 & 0 & 0 & 0 & 1 & 0 & 0 & 0 & 0.5 & 1 \\
\hline bh 324 & 0 & 0.5 & 0 & 0 & 0 & 1 & 0 & 0 & 0 & 0.5 & 0 & 0 & 0.5 & 0 & 0 & 1 & 0 & 0 & 0 \\
\hline bh 239 & 0.5 & 0 & 0 & 0 & 0.5 & 0.5 & 0 & 0 & 1 & 0 & 1 & 0.5 & 0 & 0 & 0 & 0 & 1 & 0 & 0 \\
\hline bh 19 & 0 & 0 & 0 & 0 & 0.5 & 1 & 0 & 0 & 0 & 0 & 0.5 & 1 & 0.5 & 0 & 0 & 1 & 0 & 0 & 1 \\
\hline bh 325 & 0 & 0 & 0 & 0 & 0 & 1 & 0.5 & 1 & 0 & 0 & 0 & 0 & 0.5 & 1 & 0 & 0 & 0 & 1 & 0 \\
\hline bh 433 & 0 & 0 & 0.5 & 0 & 0 & 0 & 0.5 & 0 & 0 & 0 & 0 & 0 & 0.5 & 0 & 0 & 0 & 1 & 0 & 0 \\
\hline bh 366 & 0 & 0 & 0 & 0 & 0 & 1 & 1 & 0 & 0.5 & 0 & 0 & 0 & 0 & 0 & 0.5 & 0.5 & 0 & 0.5 & 0 \\
\hline bh 376 & 0 & 0 & 0 & 1 & 0 & 0 & 0 & 0 & 0 & 0 & 0 & 0 & 0 & 0 & 1 & 0 & 0 & 0 & 0 \\
\hline bh 336 & 0.5 & 0 & 0 & 0 & 0 & 0.5 & 0 & 0 & 0 & 0 & 1 & 0 & 1 & 0 & 1 & 0 & 0 & 0.5 & 0 \\
\hline bh 444 & 0 & 0 & 0 & 0 & 0 & 0 & 0 & 0 & 0 & 0 & 0 & 0 & 0 & 0 & 0 & 0 & 0 & 0 & 0.5 \\
\hline
\end{tabular}


용하였다.

\section{2. 발정시작시각 감지 기준}

시간대별로 누워 있는 행동 비율이 비발정구 간(0), 비발정구간과 발정구간사이의 구간(0.5) 및 발정구간(1) 중에서 어느 구간에 해당되느냐 에 따라 $0,0.5$, 또는 1 중에서 한 값을 부여한 후 0.5 이상의 값이 얼마나 연속하여 나타나는 지 알아보았는데, 그 결과의 예는 Table 1 및 Table 2와 같다.

Table 1 과 같이 비발정기 모돈의 경우 대체 적으로 0 이 많이 출현되며, 또한 0.5 이상의 값 이 연속적으로 네 번 이상 출현되지 않는 것을 알 수 있다. 반면에 발정기 모돈의 경우에는 Table 2와 같이 0.5 이상의 값이 네 번 이상 연 속적으로 출현되는 것을 알 수 있다. 따라서 이처럼 0.5 이상의 값이 네 번 이상 연속적으
로 출현하고 이들 중에 최소 한 번은 1 이 포함 되었을 때 발정이 시작된 것으로 판단하였으 며, 0.5 값이 네 번 이상 연속적으로 나타나기 시작한 처음 시각을 발정시작시각으로 판단하 였다. 예를 들면, Table 2에서 bh 278의 경우 13시대부터 20시대까지 0.5 이상이 연속적으로 여섯 번 출현하였고 1 이 한 번 이상 포함되었 기 때문에 이날 13 시에 발정이 시작되었다고 판단하였다.

\section{3. 실험장치의 성능}

(1) 발정시작시각 감지 성능 분석

실험장치구에 배치된 총 40 두의 모돈을 대상 으로 실험장치의 발정시작시각 감지 성능을 평 가하였는데, 그 결과는 Fig. 6과 같았다. 40 두 모두가 발정기 동안에 발정시작시각이 감지되 었으며, 이 중에서 39 두는 처음 승가허용자세

Table 2. The continuity of more than 0.5 during estrus

\begin{tabular}{c|c|c|c|c|c|c|c|c|c|c|c|c|c|c|c|c|c|c|c}
\hline $\begin{array}{c}\text { Hour } \\
\text { Sow }\end{array}$ & 01 & 02 & 03 & 04 & 05 & 06 & 07 & 10 & 11 & 12 & 13 & 14 & 15 & 18 & 19 & 20 & 21 & 22 & 23 \\
\hline \hline bh 278 & 0.5 & 0 & 0 & 0.5 & 1 & 1 & 0 & 0 & 0 & 0 & 1 & 1 & 1 & 1 & 0.5 & 1 & 0 & 1 & 1 \\
\hline bh 425 & 1 & 0 & 1 & 1 & 1 & 1 & 1 & 0 & 0.5 & 1 & 1 & 1 & 1 & 1 & 1 & 0 & 1 & 0.5 & 0 \\
\hline bh 427 & 1 & 0 & 0 & 0 & 0 & 1 & 1 & 0 & 1 & 0 & 0 & 1 & 1 & 1 & 0.5 & 0.5 & 1 & 1 & 1 \\
\hline bh 324 & 0 & 0 & 0 & 0 & 0 & 1 & 0 & 0 & 0 & 0.5 & 1 & 1 & 0.5 & 1 & 1 & 0 & 0 & 0.5 & 1 \\
\hline bh 239 & 1 & 0 & 0 & 1 & 1 & 1 & 1 & 1 & 1 & 1 & 1 & 1 & 1 & 0.5 & 0 & 0 & 1 & 0 & 0 \\
\hline bh 19 & 0 & 0 & 0 & 0 & 0.5 & 1 & 0 & 0 & 0 & 0 & 1 & 1 & 0.5 & 1 & 1 & 1 & 0 & 0.5 & 1 \\
\hline bh 325 & 0 & 0 & 0 & 0 & 0 & 1 & 1 & 1 & 0 & 0 & 1 & 1 & 1 & 1 & 1 & 1 & 0 & 1 & 0 \\
\hline bh 433 & 0 & 0 & 1 & 1 & 1 & 1 & 1 & 1 & 0 & 1 & 1 & 1 & 1 & 1 & 1 & 1 & 1 & 1 & 1 \\
\hline bh 366 & 0 & 0 & 0 & 0 & 0 & 1 & 1 & 0 & 0.5 & 0 & 0 & 0 & 0 & 1 & 1 & 1 & 1 & 0.5 & 1 \\
\hline bh 376 & 0 & 0 & 0 & 1 & 0 & 1 & 1 & 1 & 1 & 1 & 1 & 1 & 1 & 1 & 1 & 1 & 0 & 1 & 1 \\
\hline bh 336 & 0.5 & 0 & 0 & 1 & 1 & 0 & 1 & 1 & 1 & 1 & 1 & 1 & 1 & 0 & 1 & 0 & 0 & 0.5 & 0 \\
\hline bh 444 & 0.5 & 1 & 1 & 0 & 1 & 1 & 1 & 1 & 1 & 1 & 1 & 1 & 0 & 1 & 1 & 1 & 1 & 0 & 0.5 \\
\hline
\end{tabular}




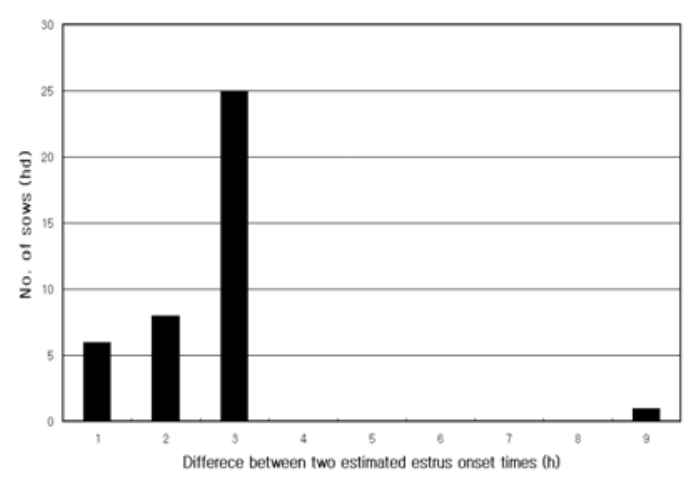

Fig. 6. Difference between two estrus onset times estimated using the traditional method and experimental device.

를 나타낸 시각을 기준하여 5시간을 뺀 시각을 발정시작시각으로 판단한 결과와 3시간 이하 의 오차를 보였으나 1 두는 9 시간의 오차를 보 였다.

(2) 생산성 분석

대조구와 실험장치구의 발정감지율, 수태율, 분만율, 산자수, 사산수, 미이라수를 조사한 결 과는 Table 3 과 같다. 대조구의 경우에는 처음 승가허용자세를 나타낸 시각을 기준으로 약 12 시간 후와 24시간 후에 인공수정을 실시하였으
며, 실험장치구의 경우에는 실험장치가 예측한 인공수정적기에 한하여 1 회 인공수정을 실시하 였다. 대조구의 발정감지율은 $95 \%$ 이었으나, 실 험장치구의 발정감지율은 $100 \%$ 이었다. 그러나 수태율과 분만율은 92.5\%로 동일하게 나타났으 며, 산자수, 사산수 및 미이라수도 차이가 없었 다 $(\mathrm{p}<0.05)$. 대조구의 경우 발정이 감지된 모돈 38 두 중에서 1 두가 수태가 되지 않았는데, 이 에 대한 이유는 언제 발정이 시작되었는지 정 확히 알지 못하여 적기에 수정을 하지 못하였 거나 배란시간이 다른 개체들과 많은 차이를 나타내었기 때문인 것으로 추측된다. 또한 실 험장치구의 경우 40 두 중에서 1 두가 발정시작 시각에서 9 시간의 오차를 보여 적기에 인공수 정이 실시되지 못하여 수태가 되지 않은 것으 로 판단되며, 수태가 되지 않은 나머지 2두는 배란시간이 다른 개체들과 많은 차이를 나타내 었기 때문인 것으로 추측된다. 이러한 대조구 와 실험장치구의 발정감지율과 수태율은 Freson 등 (1998)이 적외선센서를 이용하여 발정을 감 지한 $86 \%$ 의 발정감지율과 우리나라의 전국평 균 수태율 85\%(김 등, 2002)를 고려해 볼 때, 매우 높은 수준인 것으로 판단되고 또한 실험 장치의 성능이 우수한 것으로 판단된다.

Table 3. Heat detection rate, pregnancy rate, and average litter size of the control group and device group

\begin{tabular}{lcc}
\hline \multicolumn{1}{c}{ Item } & Control group & Device group \\
\hline \hline No. of sows (hd) & 40 & 40 \\
Heat detection rate (\%) & 95 & 100 \\
No. of A.I. (times) & 2 & 1 \\
Pregnancy rate (\%) & $92.5(37 / 40)$ & $92.5(37 / 40)$ \\
Farrowing rate (\%) & $92.5(37 / 40)$ & $92.5(37 / 40)$ \\
Piglets born alive/sow (hd) ${ }^{1)}$ & $8.7 \pm 0.05$ & $8.6 \pm 0.04$ \\
Piglets stillborn/sow (hd) & $0.8 \pm 0.02$ & $0.8 \pm 0.01$ \\
Piglets mummified/sow (hd) & - & - \\
\hline
\end{tabular}

1) Mean \pm S.D. 


\section{IV. 요 약}

스톨에서 개별적으로 사육되는 모돈은 비발 정기에 비하여 발정기에 앉아 있거나 서 있는 행동을 많이 나타내기 때문에 누워 있는 행동 비율의 감소를 나타낸다. 따라서, 본 연구는 발 정이 시작되면 활동량이 증가하는 모돈의 특성 을 이용하여 발정시작시각을 자동으로 감지하 고 이를 기준으로 인공수정적기를 예측할 수 있는 인공수정적기 예측 장치를 개발한 후 이 에 대한 성능을 평가하고자 수행되었으며, 그 연구 결과를 요약하면 다음과 같다.

1. 스톨에서 개별적으로 사육되는 버크셔 $\times$ 햄프셔 교잡종(F1) 경산돈 50 두를 녹화한 후 시간대별로 누워 있는 행동의 비율을 측정하였 다. 누워 있는 행동에 대한 발정 2일 전 24시 간 데이터와 발정 당일 24시간 데이터를 비교 하여 유의차가 나타나지 않은 00 시대, 08시대, 09시대, 16시대, 그리고 17시대의 데이터를 제 외한 나머지 시간대의 데이터만을 발정시작시 각의 감지 기준을 설정하는데 이용하였다.

2. 시간대별로 누워 있는 행동 비율이 비발 정구간에 포함되면 0 , 비발정구간과 발정구간 사이에 포함되면 0.5 , 발정구간에 포함되면 1 을 부여한 후, 0.5 이상의 값이 네 번 이상 연속 되고 그 중 1 이 한 번 이상 포함되었을 경우 발정으로 판단하였으며 네 번 이상 0.5 이상의 값이 출현되는 처음 시간대를 발정시작시각으 로 판단하였다. 그리고 발정시작시각 후 26시 간부터 34시간 사이를 수정적기로 판단하였다.

3. 인공수정적기 예측 장치는 모돈의 누워 있는 행동과 서 있거나 앉아 있는 행동 비율을 측정할 수 있도록 LED lamp, CCD 카메라, 멀 티플렉서, PC 등으로 구성하였으며, 인공수정 적기 예측 장치의 프로그램은 LabWindows/ CVI (Version 6.0.1)로 작성하였다. 인공수정적기 예측 장치에 의해 예측된 수정적기에 1 회 인공 수정한 결과, 수태율과 분만율이 대조구와 동 일하게 92.5\%로 나타났으며, 또한 산자수, 사산
수, 미이라수가 대조구와 유의적으로 차이가 없었다 $(\mathrm{p}<0.05)$.

이상의 결과를 종합해 볼 때, 인공수정적기 예측 장치로 발정시작시각을 감지하고 수정적 기에 1 회 인공수정을 시킴으로써 2회 이상 인 공수정을 시키는 관행방법에 비하여 번식성적 의 저하 없이 노동력을 절감하고 정액비 등의 비용을 절감할 수 있을 것으로 판단된다.

\section{$\mathrm{V}$. 인 용 문 헌}

1. Altman, M. 1941. Interrelations of the sexcycle and behavior of the sow. J. Comp. Psychology 31:481-498.

2. Bressers, H. P. M., Te Brake, J. H. A. and Noordhuizen, J. P. T. M. 1991. Oestrus detection in group-housed sows by analysis of data on visits to the boar. Appl. Anim. Behav. Sci. 31:183-193.

3. Diehl, J. R., Day, B. N. and Flowers, W. 2001. Pork Industry Handbook - Estrus or Heat Detection, Purdue University Cooperative Extension Service. PIH-64, p. 1.

4. Erez, B. and Hartsock, T. G. 1990. A microcomputer-photocell system to monitor periparturient activity of sows and transfer data to a remote location. J. Anim. Sci. 68:88-94.

5. Evans, L., Britt, J., Kirkbride, C. and Levis, D. 2001. Pork Industry Handbook - Troubleshooting Swine Reproduction Failure, Purdue University Cooperative Extension Service. PIH-96, p. 3.

6. Freson, L., Godrie, S., Bos, N., Jourquin, J. and Geers, R. 1998. Validation of an infra-red sensor for oestrus detection of individually housed sows. Computers and Electronics in Agriculture 20: 21-29.

7. Houpt, K. A. 1991. Domestic Animal Behavior. Iowa State University Press, Ames, p. 144.

8. Ingram, D. L., Walters, D. E. and Legge, K. F. 1980. Variations in motor activity and in food and water intake over $24 \mathrm{~h}$ periods in pigs. J. 
Agric. Sci. 95:371-380.

9. Mistlberger, R. E., Houpt, T. A. and Moore-Ede, M. C. 1990. Food-anticipatory rhythms under 24-hour schedules of limited access to single macronutrients. J. Biol. Rhythms 5:35-46.

10. Morrison, S. R., Hintz, H. F. and Givens, R. L. 1968. A note on effect of exercise on behaviour and performance of confined swine. Anim. Prod. 10:341-344.

11. Nissen, A. K., Soede, N. M., Hyttel, P., Schmidt, M. and D'Hoore, L. 1997. The influence of time of insemination relative to time of ovulation on farrowing frequency and litter size in sows, as investigated by ultrasonography. Theriogenology 47:1571-1582.

12. Perez, J. M., Mornet, P. and Reat, A. 1986. Le porc et son elevage. Maloine, Paris, France. p. 575.

13. Soede, N. M., Wetzels, C. C. H., Zongdag, W., de Konning, M. A. I. and Kemp, B. 1995. Effects of time of insemination relative to ovulation, as determined by ultrasonograpy, on fertilization rate and accessory sperm count in sows. J. Reprod. Fertil. 104:99-106.

14. Soede, N. M. and Kemp, B. 1996. Timing of AI and ovulation in sows. Reprod. Dom. Anim. 31:201-207.

15. Taylor, L. and Friend, T. 1988. Effect of housing on in situ postures of gestating gilts. Appl. Anim. Bhav. Sci. 19:265-272.

16. Weitze, K. F., Wagner-Rietschel, H., Waberski, D., Richter, L. and Krieter, J. 1994. The onset of heat after weaning, heat duration, and ovulation as major factors in AI timing in sows. Repod. Dom. Anim. 29:433-443.

17. Worobec, E. K., Duncan, I. J. H. and Widowski, T. M. 1998. The effects weaning at 7, 14 and 28 days on piglet behaviour. Appl. Anim. Bhav. Sci. 63:172-182.

18. 김인철. 2002. 새로운 돼지 사육기술-돼지인공수 정. 축산기술연구소. p. 124.

(접수일자 : 2007. 5. 31. / 채택일자 : 2007. 9. 5.) 